\title{
A case of a long-neglected basal cell carcinoma on the scalp
}

\section{Hiroki Furukawa, Junko Sowa-Osako, Toshiyuki Ozawa, Takashi Hashimoto, Daisuke Tsuruta}

\author{
Department of Dermatology, Osaka City University Graduate School of Medicine, Osaka, Japan
}

Corresponding author: Takashi Hashimoto, M.D., Ph.D, E-mail: hashyt@gmail.com

Sir,

A 73-year-old Japanese male first noticed a bean-sized lump on the scalp twenty years ago, which gradually became larger and more friable. The patient concealed the mass with a hat and pursued no medical consultation before visiting us. As for the past medical history, the patient underwent cholecystectomy ten years ago and distal antrectomy for an antral gastric cancer seven years ago. He also had diabetes, hypertension, hyperlipidemia, renal dysfunction, and bilateral knee osteoarthritis.

On physical examination, the well-developed and well-nourished patient showed a rounded, flat, friable, and malodorous tumor mass $10 \times 15 \mathrm{~cm}$ in size spreading from the right frontal scalp to the upper right eyelid (Fig. la). There was no palpable cervical or preauricular lymphadenopathy. Dermoscopy revealed ulceration, large blue-gray ovoid nests, and an arborizing vessel [1], suspicious of basal cell carcinoma (Fig. lb). Laboratory investigation revealed normocytic anemia, decreased renal function, and elevated levels of serum amylase and LDH. CT of the head revealed invasion of the tumor into the subcutaneous fat tissue but not into the bone. There was no metastasis.

Under the diagnosis of basal cell carcinoma, the tumor mass was excised to the level below the galeal aponeurosis with a $1 \mathrm{~cm}$ margin. The wound was temporally closed by synthetic dermis (Teldermis ${ }^{\circledR}$, Olympus Terumo Biomaterial Co., Ltd., Tokyo, Japan).
Histopathology of a specimen from the surgically excised tumor revealed a pedunculated exophytic tumor and invasion up to the subcutaneous tissue (Fig. lc). The surgical margins were free of tumor. The subepidermal tumor mass showed a palisading arrangement and proliferation of the surrounding connective tissue with a cleft formation between them (Fig. ld). Furthermore, the tumor tissue had continuity with the epidermis (Fig. ld). Basaloid tumor cells showed a high nucleocytoplasmic ratio, large elliptical nuclei, and low atypism (Fig. le).

After a histopathological evaluation of the excised tumor, second surgery with a skin graft from the abdomen was performed with a good result.

Management for patients with long-neglected externally visible masses is challenging [2]. Such patients tend to carry negative traits, such as depression, on the Minnesota Multiphasic Personality Inventory (MMPI-2) [3]. A French study of patients with head and neck cancers revealed that patients at a later stage of the disease tended to be more isolated, less involved with their spouses, and less anxious [4].

Our patient was socially vulnerable and did not receive enough public assistance. Fortunately, although scalp basal cell carcinomas are generally aggressive [5], and although the tumor in our patient was very large, it was not markedly invasive. However, our patient first refused the treatment of the mass. This was speculated to reflect the resignation from the treatment due to insufficient financial support and a sense of imminent death due to the severe disease. This case highlights

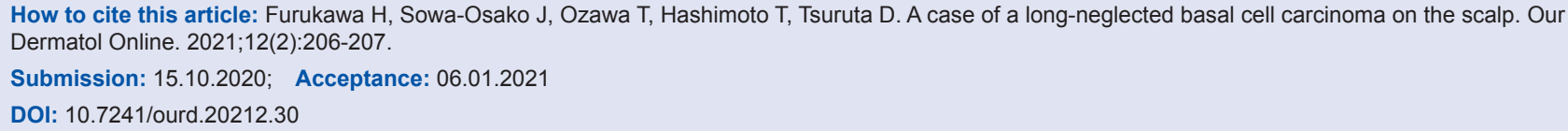




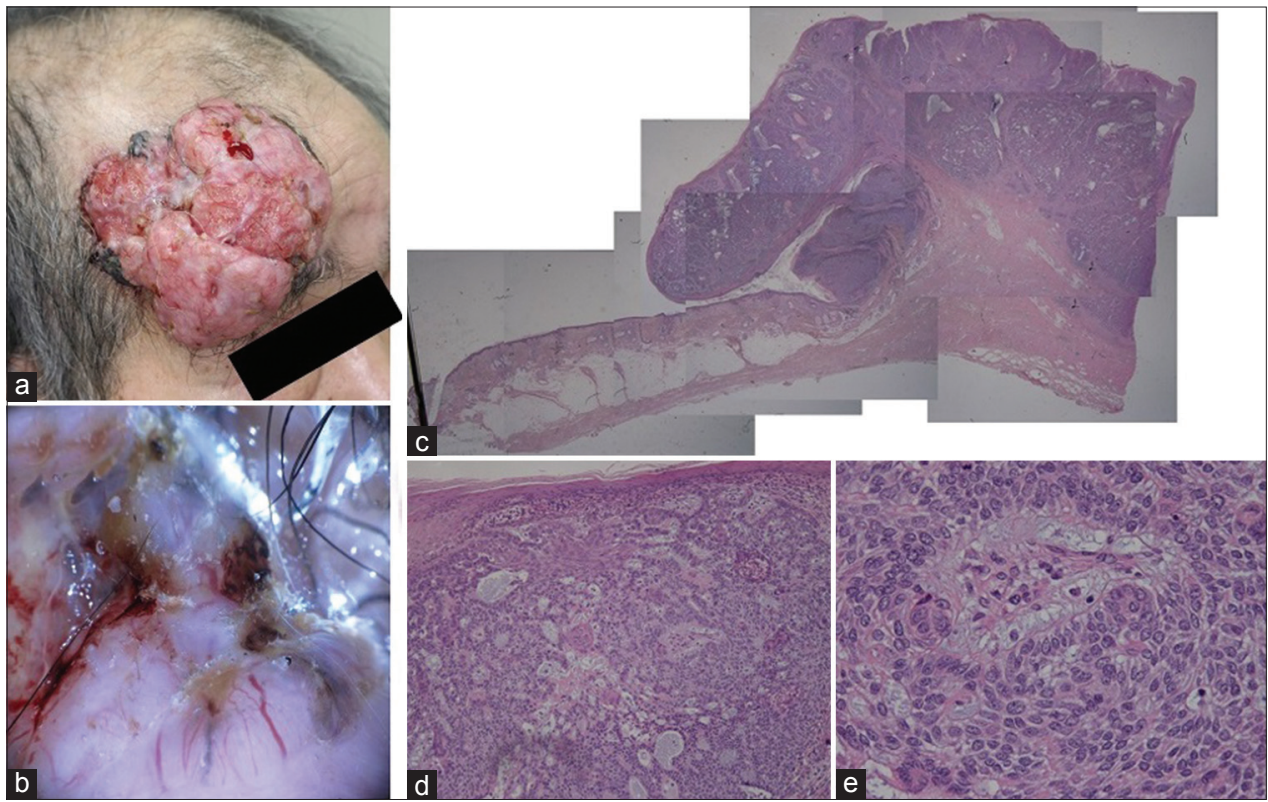

Figure 1: Clinical, dermoscopic, and histopathological features of this case. (a) A large tumor on the forehead. (b) Dermoscopic images. (c-e) Histopathological findings in a skin biopsy under magnification: (c) 20x, (d) 100x, and (e) 400x (H\&E).

the need for psychosocial care for patients with long-neglected externally visible masses of skin tumors.

The patient provided written informed consent for publication.

This study was approved by the Ethical Committee of Osaka City University Graduate School of Medicine.

\section{Consent}

The examination of the patient was conducted according to the principles of the Declaration of Helsinki.

The authors certify that they have obtained all appropriate patient consent forms, in which the patients gave their consent for images and other clinical information to be included in the journal. The patients understand that their names and initials will not be published and due effort will be made to conceal their identity, but that anonymity cannot be guaranteed.

\section{REFERENCES}

1. Wozniak-Rito A, Zalaudek I, Rudnicka L. Dermoscopy of basal cell carcinoma. Clin Exp Dermatol. 2018;43:241-7.

2. Cameron MC, Lee E, Hibler BP, Barker CA, Mori S, Cordova M, et al. Basal cell carcinoma: Epidemiology; pathophysiology; clinical and histological subtypes; and disease associations. J Am Acad Dermatol. 2019;80:303-17.

3. Pavan C, Bassetto F, Vindigni V. Psychological aspects of a patient with neglected skin tumor of the scalp. Plast Reconstr Surg Glob Open. 2017;5:e1395

4. Rozniatowski O, Reich M, Mallet Y, Penel N, Fournier C, Lefebvre JL. Psychosocial factors involved in delayed consultation by patients with head and neck cancer. Head Neck. 2005;27:274-80.

5. Castanheira A, Soares P, Boaventura P. Scalp basal cell carcinoma: A different entity? Dermatol Ther. 2019;32:e12828.

Copyright by Hiroki Furukawa, et al. This is an open access article distributed under the terms of the Creative Commons Attribution License, which permits unrestricted use, distribution, and reproduction in any medium, provided the original author and source are credited.

Source of Support: Nil, Conflict of Interest: None declared. 